\title{
Assessment of analgesic drugs in soft tissue injuries presenting to an accident and emergency department-a comparison of antrafenine, paracetamol and placebo
}

\author{
C. DE GARA \\ M.B., B.S., F.R.C.S. (Edin.) \\ M. TAYLOR \\ M.B., B.S. \\ A. HEDGES \\ Ph.D. \\ Accident and Emergency Department, and Department of Clinical Pharmacology, St Bartholomew's Hospital, \\ London ECIA $7 B E$
}

\section{Summary}

In a preliminary dose-finding study in patients following abdominal hysterectomy, antrafenine was found to be an effective analgesic in single oral doses of 300-600 mg.

A double-blind controlled between-patient study was carried out to compare antrafenine (up to 1200 mg daily), paracetamol (up to $\mathbf{4} \mathbf{g}$ daily) and placebo as analgesic in the control of pain produced by ligamentous knee or ankle injuries, low back pain or rib injuries. The only significant difference $(P<0.05)$ noted between drug treatments was a longer duration of analgesic activity following antrafenine.

The implications of these results for the study of potential analgesic drugs in soft tissue injuries are discussed.

\section{Introduction}

Antrafenine, an ester derivative of anthranilic acid, is a non-narcotic analgesic agent. Pharmacological studies have demonstrated analgesic and some antiinflammatory activity; the activity is associated with inhibition of prostaglandin synthesis and has been confirmed in controlled clinical studies (Berry et al., 1980; Manoury et al., 1979; Wisanto et al., 1981). The faecal blood loss after antrafenine $450 \mathrm{mg} /$ day or 900 $\mathrm{mg} /$ day was similar to that after placebo and significantly less than after aspirin $1.8 \mathrm{~g}$ /day (Bown et al., 1980).

This clinical trial, which was carried out in two separate parts, was designed first to establish an effective analgesic dose for antrafenine, and then to compare the efficacy of antrafenine, paracetamol and placebo in the relief of pain following soft tissue injury.

The first part of the study was carried out in female patients admitted to St Bartholomew's Hospital for total hysterectomy and the second part was carried out in out-patients, admitted to the hospital Accident and Emergency department.

First study - to establish an effective analgesic dose for antrafenine

\section{Materials and methods}

Twenty-two female patients who had undergone total hysterectomy in the preceding $72 \mathrm{hr}$ volunteered to participate in this part of the study. After narcotic intramuscular analgesics were discontinued, each patient was given a single dose of antrafenine as the first dose of oral analgesic medication in the postoperative period.

The doses of antrafenine used were $150 \mathrm{mg}, 300$ $\mathrm{mg}, 450 \mathrm{mg}$ and $600 \mathrm{mg}$; it was planned to administer each dose to 5 patients. The strength of the antrafenine used was $150 \mathrm{mg}$ and to ensure controlled conditions matching placebo tablets were used so that each dose of test analgesic consisted of four identical tablets.

Each analgesic dose was given to all patients at the same time of day and assessment of pain relief was made hourly for $3 \mathrm{hr}$ following the dose and finally when another dose of oral analgesic was requested. Pain relief was estimated by the patients using visual analogue scales, and the investigator assessed pain relief by direct question using a pain score (Hedges $e t$ al., 1977).

\section{Results}

In total, 22 patients were involved in the study -3 patients at $150 \mathrm{mg}$ dose, 6 patients at $300 \mathrm{mg}$ dose, 7 patients at $450 \mathrm{mg}$ dose and 6 patients at $600 \mathrm{mg}$ dose. A satisfactory analgesic effect was demon- 
strated in all patients taking $300 \mathrm{mg}, 450 \mathrm{mg}$ and 600 $\mathrm{mg}$. The pain analogue results are shown in Fig. 1. Antrafenine at all dose levels was well tolerated; any side effects noted were mild.

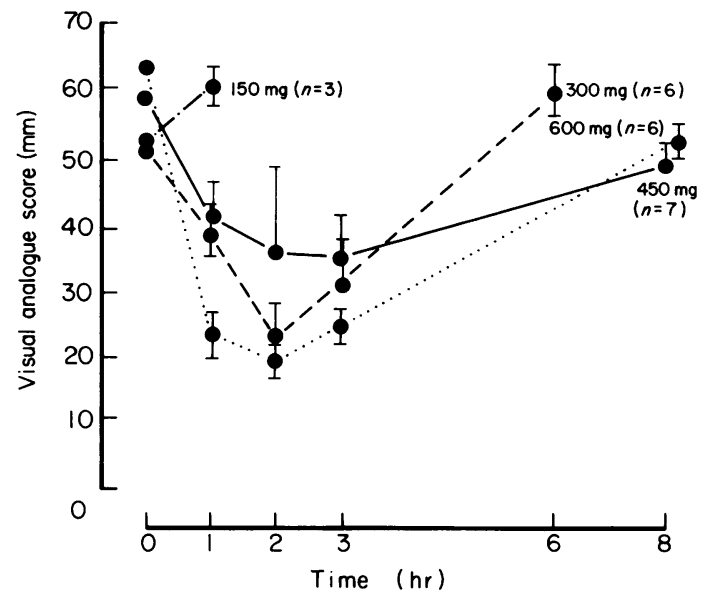

FIG. 1. Visual analogue scores at various times after administration of single oral doses of antrafenine $150 \mathrm{mg}, 300 \mathrm{mg}, 450 \mathrm{mg}$ or $600 \mathrm{mg}$ to patients who had undergone hysterectomy operations. The number of patients in each group is shown in brackets. Visual analogue scale: 0 , no pain at all; 100 , the most pain ever experienced.

Second study-comparison of antrafenine, paracetamol and placebo

Following the initial study in post hysterectomy pain, it was decided to investigate further the efficacy of antrafenine in a comparative study in patients with soft tissue injury. All patients entered in this part of the study were out-patients attending the Accident and Emergency Department at St Bartholomew's Hospital. It was considered that this study would permit evaluation of this method of screening analgesic drugs in a casualty department. The approval of St Bartholomew's Hospital ethical committee was obtained to carry out this study.

\section{Materials and methods}

The patients admitted to the second part of this study were treated for ligamentous knee or ankle injury, low back pain or rib injury. Absence of bone injury was determined by X-ray and confirmed by the radiology registrar. All patients entered the study voluntarily and written informed consent was obtained. We excluded patients with a history of acute or chronic hepatic insufficiency, mental retardation, pregnancy, history of alcoholism or drug dependence or long-term treatment with other analgesics.

The study was carried out under double blind conditions using a random block design. Patients were allocated into one of the three drug treatment groups, i.e. antrafenine, paracetamol or placebo, according to a randomization sequence.

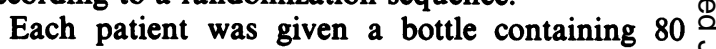
tablets of either antrafenine, paracetamol or placebo and a record card to note daily pain intensity, pain relief and number of tablets taken (Fig. 2).

Day

1) Did the tablets help you? $\square$ yes $\square$ no

2) How bad was your pain today?

No pain

The most at all pain ever experienced

3) How much did the tablets help your pain?

$\begin{array}{ll}\text { Helped } & \text { Did not } \\ \text { a lot } & \text { help }\end{array}$

4) How many tablets have you taken today?

5) Have you taken tablets today: (Please tick correct box)

Once
Twice
Three times
Four times

6) How soon did the pain return? (Please tick correct box)

Pain was not helped
Less than one hour
One to two hours
Two to three hours
Three to four hours
More than four hours?

FIG 2. An example of the daily record card the More than four hours? patients were asked to complete.

The patients were asked to complete the booklet at the end of each day answering the questions:

'Did the tablets help you?'

'How many tablets did you have to take?'

'How often did you have to take the tablets?'

'How soon did the pain return?'

They were asked to complete an analogue rating 9 scale by marking a cross on a $10 \mathrm{~cm}$ line in answer to the questions:

'How bad was your pain today?'

'How much did the tablets help your pain?' Careful instruction was given to all patients on dosage and how to complete the pain relief scores and analogue scales. After 10 days the patients were asked to return and were examined by one of the two investigators (M.T. or C. de G.) who assessed the degree of improvement, noted any side effects and counted the number of tablets returned. 


\section{Dosage used}

From the first study, it was considered that single doses of antrafenine $300 \mathrm{mg}$ would be most satisfactory. A previous study in osteoarthritis (Berry et al., 1980) has also demonstrated significant analgesic activity in daily divided doses of $450 \mathrm{mg} /$ day and 900 $\mathrm{mg} /$ day.

In this part of the study a flexible dosage was considered necessary in order that patients could take their analgesic according to their individual needs. Also, to maintain double-blind conditions, a comparative analgesic agent had to be chosen which would be effective in this indication and could also be given in the same dosage regimen as antrafenine. Paracetamol was considered to be such a suitable analgesic and patients were instructed to take one or two tablets every 4-6 hr, to a maximum of 8 tablets per day,

e.g. for antrafenine: $150-300 \mathrm{mg}$ 4-6 hourly as required.

for paracetamol: $500-1000 \mathrm{mg} \mathrm{4-6}$ hourly as required.

As a placebo group was also included in the design, patients were permitted to take a 'rescue' analgesic. Patients were instructed to take aspirin if they obtained inadequate relief from the trial drug.

\section{Analysis of data}

Many patients entered in the study did not require analgesic therapy for the suggested 10 days. Statistical analysis was therefore carried out on the pain relief scores and analogue scales obtained from the first 3 days of drug treatment only.

A second analysis was also performed on the data obtained from all subjects from day 1 to day 8 . If patients did not take their tablets for all days, but provided data for a minimum of 3 days, the results from the patients' last day of treatment were repeated up to day 8 , to account for the missing data.

The statistical analyses of pain scores and pain relief data were carried out by computing a global measure of pain intensity and analgesic relief, considering the area under the curve obtained from the individual pain and relief scores from day 1 to day 3 and day 1 to day 8 . The global measures of pain intensity and pain relief were analysed using a one factor analysis of variance.

The homogeneity of the three drug treatment groups was tested comparing age, sex, diagnosis and initial pain intensity by means of a one factor analysis of variance or $\chi^{2}$ squared test.

Mean duration of analgesic activity, daily tablet intake, patient and doctor overall assessment of analgesic activity were compared in the three drug treatment groups using non parametric analysis of variance (Kruskall-Wallis test).

\section{Results}

Of the 166 patients who entered the study, it was possible to evaluate results of only 91 . Fifty-nine patients failed to return for follow up and their final assessment was incomplete. Of the 107 patients who did complete the study, the results of 15 of these patients could not be analysed because of inadequate records.

A summary of the number of patients in each diagnosis category and the analgesic treatment administered is given in Table 1 . There was no significant difference in the homogeneity of the three drug treatment groups, comparing age, sex, initial pain intensity or distribution of diagnosis.

TABLE 1. Diagnosis and analgesic treatment (number of patients)

\begin{tabular}{lcccc}
\hline & Antrafenine & Paracetamol & Placebo & Total \\
\hline Sprained ankle & 15 & 16 & 17 & 48 \\
Low back pain & 4 & 11 & 10 & 25 \\
Rib cage injury & - & 3 & 3 & 7 \\
Other & 6 & 4 & 2 & 11 \\
Total & 25 & 34 & 32 & 91 \\
\hline
\end{tabular}

In the analysis of pain relief data, the results of 88 patients were included in the 1-3 day analysis and 90 patients were included in the 1-8 day analysis. (1 patient included in the 1-3 day analysis was not included in the 1-8 day analysis).

\section{Assessment of pain relief}

The duration of analgesic activity was longer for antrafenine than paracetamol and placebo $(P$ $<0.05$-see Table 2). Otherwise no significant differences between drug treatments were found.

\begin{tabular}{|c|c|}
\hline $\begin{array}{l}\text { Duration of } \\
\text { analgesic } \\
\text { activity (hr) }\end{array}$ & \\
\hline $\begin{array}{l}\text { Group 1-Antrafenine } \\
\text { Group 2-Paracetamol } \\
\text { Group 3-Placebo }\end{array}$ & $\begin{array}{l}3.2(0.3)^{\circ} \\
2 \cdot 4(0 \cdot 3) \\
2 \cdot 4(0.3)\end{array}$ \\
\hline
\end{tabular}

The mean cumulative scores for pain intensity over the 3-day and the 8-day periods indicate a modest reduction in pain for the antrafenine group, com- 
TABLE 3. Mean cumulative pain scores (mean \pm s.e. mean) after antrafenine, paracetamol or placebo

\begin{tabular}{lcccc}
\hline & \multicolumn{2}{c}{ Number of patients } & \multicolumn{2}{c}{ Cumulative pain score } \\
& days $1-3$ & days 1-8 & days 1-3 & days 1-8 \\
\hline Group 1-Antrafenine & 25 & 25 & $93 \cdot 2(7 \cdot 4)$ & $257 \cdot 3(25 \cdot 9)$ \\
Group 2-Paracetamol & 33 & 34 & $106 \cdot 7(6 \cdot 6)$ & $271 \cdot 2(24 \cdot 9)$ \\
Group 3-Placebo & 30 & 31 & $111.0(7 \cdot 0)$ & $308 \cdot 3(29 \cdot 3)$ \\
Totals & 88 & 90 & & \\
\hline
\end{tabular}

pared with paracetamol and placebo, but this did not reach statistical significance (Table 3 ).

\section{Side effects}

The distribution of total number of side effects in the 3 treatment groups was not significantly different. Drowsiness was the most frequently reported adverse effect, noted by 4 patients in the placebo and paracetamol groups and 7 patients in the antrafenine group.

\section{Discussion}

There is a need for more effective, safe analgesics for use in clinical practice. With the results of the initial study in postoperative pain, together with information from other clinical studies, it was considered justified to investigate antrafenine in a comparative study in patients with soft tissue injury, who often need non-narcotic analgesics.

An Accident and Emergency Department should be a good centre for such a study with a large number of patients presenting who actually need such drugs. However, the results of the study which indicated no significant difference between any of the 3 treatments, (antrafenine, paracetamol and placebo) require comment. Analgesic activity of antrafenine had been shown in the first part of this investigation. A single dose of $300 \mathrm{mg}$ provided adequate pain relief for a period of 4-6 hr in patients with postoperative pain. This activity has been confirmed in doubleblind clinical trials. Paracetamol is a frequently prescribed analgesic which should provide sufficient pain relief in the majority of patients with this indication. If paracetamol had not been included, then it might have been concluded that antrafenine was ineffective.

However, the absence of a significant difference between paracetamol and placebo indicates that this investigational model using these types of soft tissue injury is insensitive to screen such analgesic compounds. This emphasizes the importance of using a known analgesic as well as placebo in the investigation of the efficacy of a new analgesic agent.

Patient compliance in this study was poor; $30 \%$ of $\overrightarrow{\vec{\omega}}$ the patients did not return for follow-up, despite $\stackrel{\omega}{\sigma}$ telephone requests and postal communication with $\bar{O}$ stamped-addressed envelopes. Of the patients who 3 did complete the study 15 patients' results had to be rejected because of inadequate records.

The results of this study suggest that it may be unnecessary to prescribe routinely an analgesic for minor soft tissue injury and follow up appointments $\stackrel{\infty}{0}$ for further consultation may not be required. Also, it 은 would appear that patients recruited in a casualty $\rightarrow$ department are unlikely to be suitable for a clinical $\gg$ trial of this nature.

\section{Acknowledgments}

We would like to thank Mr D. Caro and Professor P. Turner their encouragement and helpful advice throughout this study, Synthelabo for supplying the tablets used, and the doctors and nursing staff of the gynaecological wards of St Bartholomew's $\overline{\bar{O}}$ Hospital for their co-operation.

\section{References}

Berry, H., Gordon, A., CoQuelin, J.PH. \& Seymour, D. (1980) Comparative study of antrafenine, naproxen and placebo in osteoarthrosis. Presented at the World Conference on Clinical Pharmacology and Therapeutics, London, August 3-9th, 1980.

BOWN, R.L., MARTIN, B.K., GORDON, A., SEYMOUR, D., ROVEI, V., 3 Gomeni, G., Narbonne, G. \& CoQuelin, J.Ph. (1980) Effets б compares de l'antrafenine, de l'aspirine et d'un placebo sur les pertes sanguines digestives mesurées par la methode des hematies marquees au chrome. Therapie, 35, 685 .

Hedges, A., Rose, J., Leighton, M. \& TURner, P. (1977) A double-blind comparison of meptazinol with placebo in postoper- $ᄋ$ ative pain. Journal of Clinical Pharmacology, 17, 125.

MANOURY, P.M., DUMAS, A.P., NAJER, H., BRANCENI, D., D Prouteau, M. \& BORG, F. (1979) Synthesis and analgesic activities of some (4-substituted phenyl-1-piperazinyl)alkyl 2- $\mathrm{N}$ amino-benzoates and 2-aminonicotinates. Journal of Medical $\Omega$ Chemistry, 22, 5.

Wisanto, A., Caudron, J., Dubols, D., Narbonne, G. \& COQUELIN, J.PH (1981) A double-blind placebo-controlled single $\omega$ dose study comparing antrafenine and placebo in patients with post-episiotomy pain. Current Therapeutic Research, 29, 171. 